

\title{
IMPROVED EFFECTIVENESS OF \\ VIBRATION MONITORING OF ROLLING BEARINGS \\ IN PAPER MILLS
}

\author{
Basim Al-Najjar \\ Dept. Of Industrial Engineering, Lund University \\ Dept. Of Math. Stat. And Computer Science, Växjö University
}

\section{SYNOPSIS}

Rolling element bearing failures in paper mill machines are considered in relation to their critical role in the machine function. The paper discusses these failures according to what becomes damaged and how, and relates them to the vibration spectra and their development over the bearings' lives. Interpretation of some variations in the vibration signature, i.e. relating vibration amplitude changes and frequency shifts to the deterioration processes involved, are proposed and discussed. The literature was found mainly to confirm this analysis. A new approach to envelope alarming is presented and shown theoretically (logically) to offer later renewal with fewer failures, and therefore lower cost and higher productivity. Deficiencies in data coverage and quality, and the feedback of case study results, are discussed. A model to improve maintenance experience is proposed and discussed. Using vibration to monitor component condition, the accurate prediction of remaining life requires (a) enough vibration measurements, (b) numerate records of operating conditions, (c) better discrimination between frequencies in the spectrum and (d) correlation of (b) and (c). This is because life prediction depends on the amplitudes of (and) the frequencies generated by the component damage. Much money could be saved because some present policies utilise as little as half of the bearing useful life.

Keywords: Bearing defects, Vibration spectral analysis, Defect vibration frequency, Fault diagnosis, Envelope alarming, Data gathering and Feedback, Maintenance improvement.

\section{LIST OF NOTATION}

$\phi$ : Angle of contact.

$B d$ : Ball diameter.

$P d$ : Pitch diameter.

$n$ : Number of rolling elements.

$N$ and $X$ : Revolution per second, RPS.

$V B M$ : Vibration-based monitoring.

UPBFR: Unplanned-but-before-failure replacements are performed at unplanned but before failure stoppages to prevent the occurrence of failures.

$R M S$ : Root Mean Square.

$T Q M$ : Total Quality Management.

$B P F O$ : Ball pass frequency outer.

$B P F I$ : Ball pass frequency inner.

$B S F$ : Ball spin frequency.

$F T F:$ Fundamental train frequency.

$H z$ : Hertz, one revolution per second.

$B S$ : British Standard. 


\section{INTRODUCTION}

Vibration spectral analysis provides a basis for diagnosis of failure causes, defect development mechanisms and failure modes of most types of faults in rotating and reciprocating machines, because each machine element, failure cause and failure mode generates identifiable frequencies $(\mathbf{1}, \mathbf{2}, \mathbf{3}, \mathbf{4}, \mathbf{5}, \mathbf{6})$. Technical knowledge concerning the machine and its operation can be improved in many ways. Analysis usually increases and deepens this knowledge (7).

Detecting failure causes, and not just imminent failures, provides possibilities to control the machine or component condition before the deterioration becomes intolerable. To assess bearing condition reliably, it is necessary to consider all the significant damage in the whole bearing, because defects may begin in one bearing part and cause damage to other parts later.

Vibration-based monitoring, (VBM), systems give early indications of changes in the machine condition $(\mathbf{5}, \mathbf{8})$. These indications could be of great importance also in detecting deviations in the product quality before they can show on quality control charts (9). In spite of using VBM programs, manufacturing machinery still experiences failures and unplanned-butbefore-failure replacements, (UPBFR). The latter arise usually when a defect develops without being detected early by the system or maintenance staff due to personnel or system error or some unexpected failure causes (8). In most cases, the effective vibration replacement level, which makes use of as much as possible of the component useful life but prevents failures, is not obvious. The problem can be stated in this way; we can detect many faults but we cannot say, in general, with a reliable degree of certainty how serious it is. The overall (RMS) vibration level, at a specific frequency or frequency band is usually used to estimate the time to replacement, and its seriousness is usually evaluated subjectively. The usual replacement rule is; replace the bearing as soon as some of the bearing defect frequencies in the spectrum reach amplitude higher than normal.

In-built, installation and operational defects are discussed in section 2. Variations in bearing defect vibration frequencies and relating these frequencies to specific types of damage to bearings is discussed in sections 3 and 4 respectively. The available alarm setting methods and a new approach for envelope alarming is proposed and discussed in section 5. A model for maintenance improvement based on the accumulated data is suggested in section 6 . Data gathering and feedback of results is discussed in section 7.

\section{FAILURE CAUSES IN ROLLING ELEMENT BEARINGS}

Bearing shape and surface properties change gradually through structural, surface and subsurface deterioration. The extent of change depends on many factors such as; construction, material, operating conditions and the deterioration process. Zaretsky $(\mathbf{1 0}, \mathbf{1 1})$ provides two good review articles on bearing life, one on metallurgy and the other on lubrication, highlighting the effect of the advances in materials on bearing life. Succi (12), discusses three different phases in the bearing life, where the second phase represents about $65 \%$ of bearing total usable life. The phases are; no defects, a defect initiated and developed, a failure is imminent. We have observed that it is often difficult to tell for certain that the second phase has begun especially when the number of measurements, e.g. vibration, is very small.

\subsection{In-Built Defects}

Implementing Total Quality Management, TQM, in bearing manufacturing processes reduced in-built defects $(\mathbf{1 3}, \mathbf{1 4})$. Defect significance may be determined by severity and/or impact on load carrying, machine productivity, safety and product quality. Defect (physical) severity can be assessed by the amplitude of the relevant detectable vibration frequencies.

Deviations in manufactured bearings from the theoretical design take various forms:

1. Geometrical irregularities in the form of waviness in the rings. 
2. Ovality of rolling elements, inner and outer rings.

3. Inaccuracies of the cage make the rollers unevenly spaced.

4. Rolling element diameter variability.

5. Variations in the bearing clearances.

6. Variation in the surface finish of the bearing's internal surfaces.

Note that even deviations within drawing tolerances have an effect which may be measurable and from which defects may develop with use. These deviations often generate particular vibration frequencies characteristic of the manufacturing process (15). All the defects which may be initiated in bearings due to bearing packaging, transport and storage are also considered as in-built defects.

\subsection{Installation and Operational Defects}

The mechanism of fatigue initiation and subsequent failure is suggested by (16) to be governed by the combined effects of film thickness, roughness and debris size. Lubrication contamination can lead to surface indentation and a subsequent reduction in fatigue life of a bearing, which fails only by fatigue if contaminant particles bridge the elastohydrodynamic lubricating film (17). Bearings fail due to spalling fatigue in spite of using recommended lubrication, correct temperature, a suitable load and contacts with pure rolling motion (18). This is why the bearing life is usually determined by surface fatigue. A loaded bearing causes a gradual development of surface irregularities. Failures in rolling element bearings can be classified into four major classes (18):

1. Wear; Surface removal, removal of loose particles, chemical or electrical removal.

2. Plastic flow; Loss of contact geometry due to cold flow, destruction by material softening due to unstable overheating.

3. Contact fatigue; Spalling, surface di-stress.

4. Bulk Failure; overload cracking, overheat cracking, bulk fatigue, fretting of fit surfaces.

In wear, the deterioration develops continuously. Fatigue usually causes a series of suddenly occurring material separation in the surfaces, i.e. spalling. Progressive wear and fatigue processes will gradually introduce geometrical errors which may be similar to or enhance the in-built defects.

Faulty installation causes defects which start quickly and develop rapidly such as; bearing misalignment, faulty loaded and/or squeezed tightly by its housing. Overheating, rapid wear and seizing are the most common failure modes in these cases. Vibration measurements straight after maintenance actions, e.g. replacements, provide quality assurance of the tasks performed. In Barkov and Barkova (19), about two thirds of the bearings that failed early had installation defects, e.g. radial tension and misalignment of the fixed race, of which about half had been operating outside specified operating conditions.

Technical knowledge of machine construction, failure analysis and tribology, with effective diagnosis and prognosis techniques will enable the maintenance engineer to assess machine present condition and predict its near future reliably. For example, wear occurs due to many causes such as pitting, oxidation, direct metal-to-metal contact due to wrong or insufficient lubricant. Each failure cause develops at a different rate and with different characteristic frequencies. The same thing can be said about deterioration rate due to crack growth because of cyclic stresses and oxidation, compared with wear due to insufficient lubricant film. Thermal expansion of a shaft is usually compensated by leaving one side free to move through the bearing otherwise it results in a hogged shaft which causes rapid bearing deterioration.

Scheithe (20) presented tables for the proportion of wear, fatigue, corrosion and deformation in the total bearing failure causes which showed that abrasive wear, fatigue and 
deformation were responsible for the most of the failures, ( $25 \%, 18 \%$ and $14 \%$, respectively) and corrosion the lowest proportion, ( $8 \%$ ). Herraty (21) found that about one third of failures are due to straightforward fatigue, one third to lubrication shortcomings and the remainder to contamination, fitting and other problems.

\section{BEARING DEFECT FREQUENCIES}

The theoretical defect vibration frequencies when the inner race is rotating, can be calculated using the following equations:

Defect on the outer race $=$ Ball pass frequency outer $=$ BPFO

$\mathrm{BPFO}=\frac{n}{2} \frac{N}{60}\left(1-\frac{B d}{P d} \cos \phi\right)$

Defect on the inner race $=$ Ball pass frequency inner $=$ BPFI

$\mathrm{BPFI}=\frac{n}{2} \frac{N}{60}\left(1+\frac{B d}{P d} \cos \phi\right)$

Ball defect $=$ Ball spin frequency $=\mathrm{BSF}$

$\mathrm{BSF}=\frac{P d}{2 B d} \frac{N}{60}\left[1-\left(\frac{B d}{P d}\right)^{2} \cos ^{2} \phi\right]$

Cage defect frequency $=$ Fundamental train frequency $=$ FTF

$\mathrm{FTF}=\frac{1}{2} \frac{N}{60}\left(1-\frac{B d}{P d} \cos \phi\right)$

see for example (1).

If the rolling elements slip on the races instead of rolling, then the actual vibration frequencies will shift (12). The records of the machine rotational speed often differ from realtime measurements of $\mathrm{N}$. $\mathrm{N}$ varies for many reasons from the production settings, e.g. technical. $\mathrm{Bd}$ and $\mathrm{Pd}$ change due to wear and spalling and get shape variation, i.e. elastic deformations, due to overloading and wrong assembly and/or installation. Bearing geometry may change with operating conditions such as overloading, wrong assembly or installation, high temperature, extent of deterioration, and/or unexpected vibration direction, i.e. exposing a radial bearing to a high axial vibration level.

The variation in the bearing geometry causes the contact angle, $\phi$, to change in response. If $\phi$ changes from 0 to $30^{\circ}$ at $\mathrm{N}=30$ RPS the defect frequencies shift about $\pm 3 \%$ (22). Therefore, it is worth noticing that sometimes the measured frequencies may deviate appreciably from the theoretical defect vibration frequencies calculated by equations (1) to (4) as a secondary effect of the defect itself or (an) other defect(s). These deviations can be used to deduce the bearing condition, defect causes and to identify their higher multiples, i.e. harmonics, and modulating frequencies. Therefore, the changes in the theoretical defect vibration frequencies should be considered when interpreting bearing vibration spectrum. One of the key features for the interpretation of vibration spectra is more accurate measurement of operational and environmental conditions such machine rotational speed, loading and temperature, so that one can be more certain of detecting these small but significant frequency shifts and amplitude differences.

\section{DEFECTS AND THEIR GENERATED FREQUENCIES}

Frequencies are specific to the bearing but the surrounding structure can damp some frequencies more than others and occasionally may resonate. The structure responds to the actual frequencies so if $\mathrm{N}$ changes the response spectrum may be quite different. High resolution of the vibration spectrum is important to distinguish close but different frequencies, e.g. $1 * X$, where $i * X$ is the ith multiple of the machine rotational frequency, $(X), i=1,2,3, \ldots$, and the second multiple of FTF, $(2 * \mathrm{FTF})$, where $2 * \mathrm{FTF} \approx 0.86^{*} \mathrm{X}$, and it is also required for 
recognition of bearing defect frequencies at a low frequency range when high vibration energy frequencies such as $1 * X$ and $2 * X$, exist (6).

The frequencies BPFI and BPFO are usually generated if roughly $60 \%$ and $40 \%$ of the total rolling elements pass over a defect on the inner and outer race, respectively $(4, \mathbf{2 3}, \mathbf{2 4}$, 25). Higher multiples of the bearing defect frequencies may be generated due to the existence of several defects at that part or the existence of several identical parts which are damaged, e.g. several damaged rolling elements (26).

Variations in the machine rotational speed and load often result in frequency and amplitude modulation. The modulation gives rise to new frequencies which are not present in the original vibration signals, at the sum and/or difference between the original frequencies. A high frequency (c), i.e. carrier, and a low frequency (f), i.e. modulating frequency, usually cause a side band of (c) with (c-f) and (c+f) alongside it. The side band amplitude is linearly related to the amplitude of the modulating signal (27).

The frequencies which represent sum and differences of the bearing defect vibration frequencies are usually generated by many phenomena, e.g. amplitude modulation, existence of a pulse with repetition frequency, due to the looseness of rotating units, because of truncated signal and because of multiple defects, for more details see (23). This is why some frequencies are modulated by, e.g. BSF, $2 * \mathrm{BSF}, 1 * \mathrm{FTF}, 2 * \mathrm{FTF}, 1 * \mathrm{X}, 2 * \mathrm{X}$. A signal can be modulated by many other frequencies at once and each creates a separate side band.

When the bearing is deformed during operation, the rolling elements may follow different courses and strike the defects on the inner or outer race at different occasions. The number of the rolling elements striking defects may then change. This means that $\mathrm{m}$ rollers may follow a particular course on some occasions while $(\mathrm{m}+1),(\mathrm{m}+2), \ldots, \mathrm{n}$ strike another set of defects at the same or on different occasions, where $m=1,2, \ldots n$, and $n$ is the total number of rollers. This may be why, in such a case, many frequencies are modulated by the machine speed and its harmonics. The probability of occurrence increases when the inner or outer races have more defects. Thus, the existence of the side bands can with high probability be interpreted as; several defects in the inner or outer race, with the rollers following different paths, so that they thrust different numbers of defects.

When the number of rolling elements and defects are equal to $n$ and $k$, respectively, then the defect frequencies generated depend upon the number of rolling elements $(n-i), i=0,1, .$. , (n-1) passing over the defects $(\mathrm{k}-\mathrm{j}), \mathrm{j}=0,1, . .,(\mathrm{k}-1)$. Thus, the frequencies generated vary from that for only one ball passing over one defect to the extreme case when $\mathrm{n}$ balls, in different groups, pass over $\mathrm{k}$ defects randomly. As the number of defects grows so does the number of multiples in the spectrum. This growth, together with the corresponding growth in amplitudes may be used to judge when the bearing is about to fail.

The time from defect initiation to imminent failure may be longer than double the time from new to defect initiation. The incipient bearing defects, which can be detected, will not prevent normal operation in the short term (18). Thus, more than half of a bearing's life is thrown away when it is replaced as soon as a deviation in its vibration level is observed especially when some disturbing factors unrelated to the general machinery condition were active temporarily. A bearing may, then, be considered functioning correctly in spite of a detectable vibration level if it is able to carry the specified loads and does not significantly affect performance efficiency, product quality and operating safety.

Excessive wear often takes place due to using unsuitable lubricant, high operating temperature, lack of lubricant, high contamination in the lubricant or sometimes dirty surroundings. High temperature reduces lubricant viscosity and consequently its ability to build an oil film able to carry the specified loads. When a wear process is active it is usual that the amplitudes of some vibration frequencies increase while others reduce, and some frequencies arise while others disappear. All these are probably due to the tribological 
changes in the contact areas, i.e. polishing and building of asperities at the contact areas lead to amplitude variations and frequency shifts. When asperities are polished out, the vibration level may fall but leave the bearing looser. This may generate other frequencies which can be used to assess damage severity. The excessive wear may result in high temperature and sticking of rolling elements which may cause the outer race to rotate with respect to the bearing housing or the inner ring with respect to the shaft. Several multiples of X can then be expected in the spectrum.

Excluding defects, which may occur during manufacturing and installation, the cage is usually the last component to become damaged and fail. Extensive wear in the races and/or rolling elements leads to damage in the cage, because rolling elements with defects impact the cage. Development of permanent damage, e.g. plastic deformation and pitting, in the rolling elements and/or cage often generates the frequencies FTF, BSF and/or their harmonics with detectable amplitudes. Thus, when some multiples of FTF are detectable, they indicate that the rolling elements, inner and/or outer race may already have defects, so a search for their defect frequencies should be made before bearing condition is assessed.

Faulty installation or thermal shaft hogging may generate several multiples of FTF. This probably occurs because the cage and the rollers are strongly squeezed by bearing housing. Therefore, the multiple index $\mathrm{i}$ may indicate the number of rollers thrusting the cage at a deformed point, when they pass over them, or the number of the deformed points which are thrusted by one roller, or a combination of both.

Sometimes, it is possible to detect several multiples of the machine rotational frequency in vibration spectra, due to one or more of the following reasons:

1. Waviness in the inner and/or outer races, and/or

2. Rotation of the outer ring in the bearing house or of the inner ring on the shaft, and/or

3. Bearing misalignment due to faulty installation of the bearing or hogged shaft.

The overall vibration level may increase when several harmonics of the machine rotational frequency and bearing defect frequencies are detectable. To differentiate between these causes; the existence of high vibration levels of $2 * \mathrm{X}$ in both the radial and axial directions indicates bearing misalignment.

In general, defects on the outer and inner rings behave in a similar manner except that the vibration amplitude of the outer ring is much more than that for the inner ring for a given size of defect, machine load and, operational and environmental conditions. This is due to:

1. The defect on the inner ring passes the loading zone only once per revolution.

2. The signal from the defect on the inner ring must travel through more structural interface than that from the outer ring to reach the transducer.

The use of vibration spectral analysis for monitoring bearings which can fail from very rapidly developing mechanisms, e.g. thermal runaway failures, is possible if the damage causes and/or damage developments are monitored. However, continuous monitoring, perhaps with an automatic trip, is necessary to ensure that the machine can be stopped before catastrophic failure. In paper mills, no records were found of such rapidly-developing failures, which are more usually associated with faster-running bearings.

\section{DYNAMIC ENVELOPE ALARMING}

When monitoring a vibration spectrum, the useful data to be observed are:

1. The significant frequencies.

2. Amplitudes of the significant frequencies.

3. New and disappeared frequencies.

4. The noise level.

The significant frequencies are those which can be utilised to assess, which machine elements are deteriorating and the damage severity, and to track defect development. 
In the commercial VBM programs, which are usually used in paper mills, there are three types of alarms; Overall alarm to monitor the overall vibration energy, envelope alarming to monitor all the spectral patterns, and selective frequency band alarming. Overall vibration energy is the main factor for establishing tables for alarm systems (28). Sometimes, more than one warning level is implemented to represent different levels of damage severity. In general, each measuring point has its own reference alarm level, which is often determined relative to the first measurement after bearing replacement $(\mathbf{2 9}, \mathbf{6})$. The statistical alarm limits are usually based on some unrealistic assumptions such as normality of the vibration measurement values even during the defect development phase (30, 31). But, in general, as soon as the overall vibration level exceeds a pre-set amplitude, the alarm is raised. Extra vibration measurements at more frequent intervals are then usually made before taking a decision on when to renew the bearing.

The alarm levels are usually set by a person not well trained for such tasks. It is rare that this person has the required knowledge of machine design, failure causes, defect development mechanisms, failure modes, identifying the significant frequencies and their relation to defects, etc. The setting of envelope alarming is, in general, done by experts and the possible changes in the machine speed, which cause frequency shift, are usually not handled reliably.

In order to use envelope alarms effectively for detecting deviations in the machine condition with a high probability, a dynamic envelope alarm is required. This consists of several warning levels and is prepared in advance, i.e. bearing significant defect frequencies are identified in the envelope alarming as multiples of the machine speed, and normalised to 1 Hz, (1 RPS). Thus, it would be applicable for identical bearings and those of approximately identical vibration signatures and independent of the machine rotational speed because frequencies are identified relative to the actual RPS. Particular warning messages arise indicating deterioration severity and which frequency(ies) is (are) involved. Three levels would, however, be necessary to indicate defect initiation, development and the replacement level (6), but this is rarely done.

Significant frequencies and amplitudes can be determined from the machine vibration history. Different operating conditions may cause variations in the vibration signature, i.e. new frequencies and different amplitudes, which were not considered in the original envelope alarming. The user should change the envelope alarming to fit the operating conditions.

Identification of defect causes is not easy for the technician especially, when thousands of measuring points are required to be assessed say monthly. But, by means of a software program, which is prepared specially for this purpose, it is possible to identify characteristic defect vibration frequencies and evaluate the state of the interesting bearings easily and effectively. The available tools are not effective enough due to their inability of considering changes in the machine speed, bearing defect frequencies and operational conditions.

Such a program can be applied in conjunction with the original VBM program and database. The assessment of the bearing state should become easier when the dynamic envelop alarming is established and has run for a while to accommodate data. Alarm setting for each measuring point should be handled by software.

\section{Example 1}

The data used in this example are not all real but they are reasonable and based on the author's practical experience within paper mill industry.

Assume that we have $n$ nominally identical rolling element bearings installed at the driven sides of $n$ drying cylinders, in a paper mill machine. In such a case the bearings can be considered to be exposed to approximately the same operating conditions, such as load, speed and temperature. 
Let the vibration frequencies which can be used to detect and follow damage developments in these bearings at an early stage be; $1 * \mathrm{BPFO}, 2 * \mathrm{BPFO}, 1 * \mathrm{BPFI}, 2 * \mathrm{BPFI}, 1 * \mathrm{SBF}, 2 * \mathrm{SBF}$, $1 * \mathrm{FTF}, 2 * \mathrm{FTF},(1 * \mathrm{FTF}+1 * \mathrm{BPFO}),(1 * \mathrm{FTF}+\mathrm{BPFI})$ and $(1 * \mathrm{SBF}+1 * \mathrm{BPFO})$, see Al-Najjar (32). Also, let the three alarm levels, i.e. defect initiation, development and replacement, of each of these frequencies be; $(0.3,0.5,0.95),(0.2,0.35,0.85),(0.25,0.4,0.9),(0.2,0.4,0.8)$, $(0.3,0.4,0.9),(0.25,0.35,0.8),(0.2,0.4,0.8),(0.15,0.3,0.6),(0.15,0.3,0.6),(0.2,0.4,0.7)$ and $(0.2,0.3,0.6)$, respectively, measured in $\mathrm{mm} / \mathrm{s}$.

These levels can be estimated from the VBM database for the machine when enough identical bearing replacements have been recorded $(6,31,32)$. Make the alarm level at each frequency cover a range equal to $1.5 \%$ at either side of the designated frequency to compensate for the variations in the bearing defect frequencies. It is possible then to set the three-level envelope alarm for the above frequencies, manually or through the software. Let the typical spectrum shown in Fig. 1 represent the vibration signal at time $t_{1} \geq 0$, when the speed is 10 RPS. Also, let the policy be: Replace at failure or as soon as the amplitude of one, or more, of the chosen frequencies approaches or exceeds its replacement level, i.e. the third alarm level.

The speed and load are, in general, adjusted to fit the production plans, and cannot be kept constant. Changes in the running speed and load usually cause the vibration frequencies to shift and amplitudes to change. For easiness, let the location of each of the chosen vibration frequencies in the envelope alarm shift to the right or left precisely the same amount of increment or reduction in the planned running speed, respectively. Also, let the alarm levels increase or decrease by double the amount of increment or reduction in the planned load, respectively.

Now, assume that at time $t_{2}>t_{1}$, the vibration and operating conditions are measured once more simultaneously, and it is found that the vibration spectrum is not appreciably changed, but the running speed and load are increased by $10 \%$ each. This means that all bearing defect frequencies are shifted by about $10 \%$ to the right of their original positions and their amplitudes are increased by at least $20 \%$.

In this case, using a three-level dynamic envelope alarm, which should be adjusted manually (or automatically), no warnings would be expected even if operating conditions are changed appreciably, (see Fig. 1).

However, this is not possible if the envelope alarm is not adjusted, which the case is in general when using commercial VBM programs including one or, sometimes, two-level envelope alarms. Thus, the replacement of the bearing is indicated even though it is still functioning. For example, frequency $b=112.1 \mathrm{~Hz}$, which has $0.5 \mathrm{~mm} / \mathrm{s}$ amplitude, will shift to the right by about $11 \mathrm{~Hz}$ and its amplitude may increase to 0.6 . This means that frequency $\mathrm{b}$ will shift to the range which is very close to that occupied previously by the frequency $(\mathrm{f}+\mathrm{b})=117 \pm 2 \mathrm{~Hz}$. In other words, frequency b would exceed the third envelope alarm level and lead to unnecessary bearing replacement, when the real amplitude of frequency $b$ remained at only $52 \%$ of the replacement level $0.95 \mathrm{~mm} / \mathrm{s}$, (see Fig. 1).

In general, using a three-level envelope alarm, whether dynamic or not, for bearing defect frequencies increases the bearing's useful life, because the bearing is usually replaced as soon as its vibration level exceeds the normal, i.e. when it is still below the second alarm level (6). 


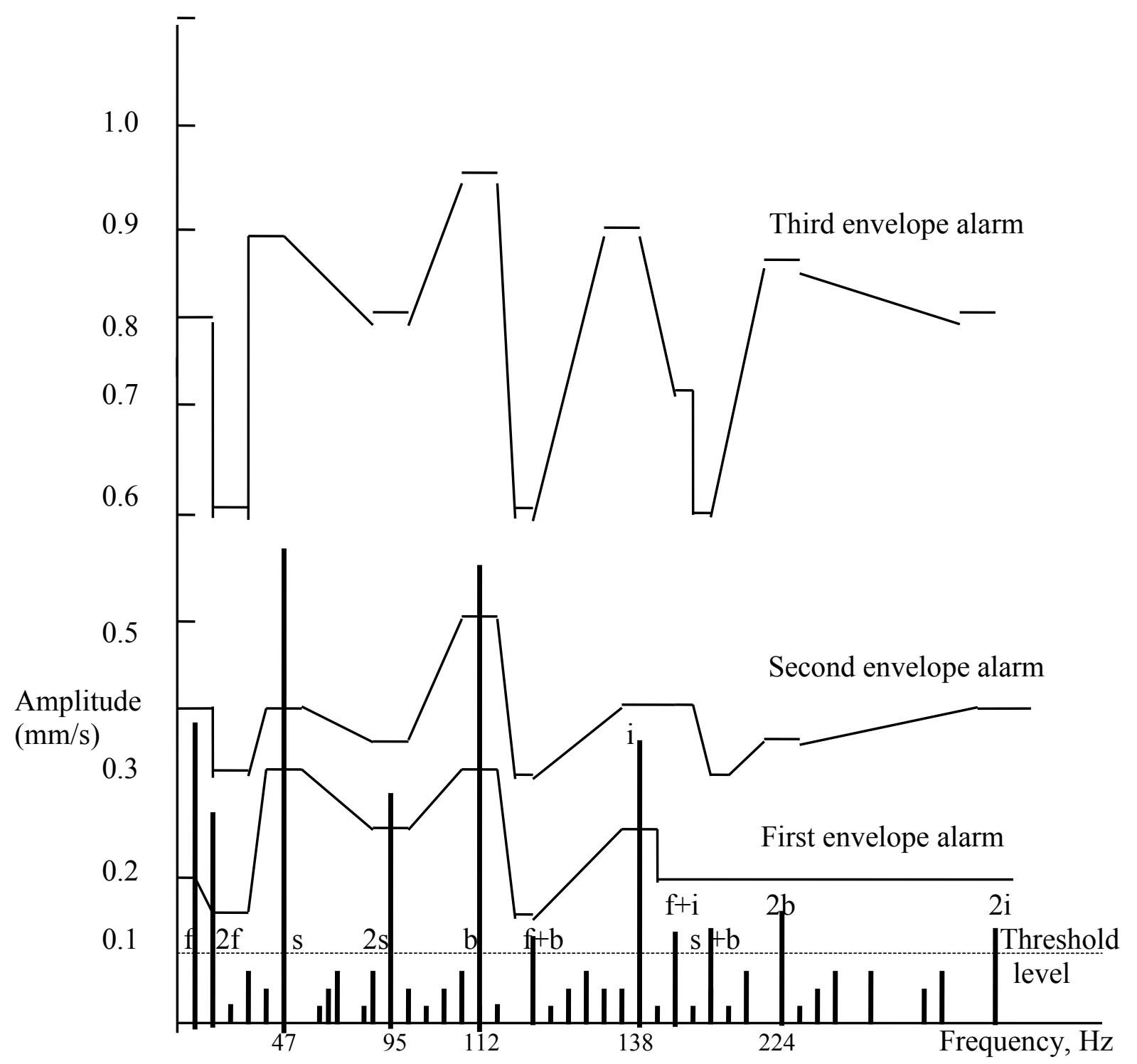

Fig. 1. A typical vibration spectrum reveals only the defect vibration frequencies of the bearing $23052 \mathrm{cck} / \mathrm{SKF}$ and the three assumed envelope alarm levels, where $b, 2 \mathrm{~b}, \mathrm{i}$, $2 \mathrm{i}, \mathrm{s}, 2 \mathrm{~s}, \mathrm{f}, 2 \mathrm{f},(\mathrm{f}+\mathrm{b}),(\mathrm{f}+\mathrm{i})$ and $(\mathrm{s}+\mathrm{b})$ are $1 * \mathrm{BPF} 0,2 * \mathrm{BPFO}, 1 * \mathrm{BPFI}, 2 * \mathrm{BPFI}, 1 * \mathrm{SBF}$, $2 * \mathrm{SBF}, 1 * \mathrm{FTF}, 2 * \mathrm{FTF},(1 * \mathrm{FTF}+1 * \mathrm{BPFO}),(1 * \mathrm{FTF}+\mathrm{BPFI})$ and $(1 * \mathrm{SBF}+1 * \mathrm{BPFO})$, respectively. The speed is assumed to be $10 \mathrm{RPS}$. For the bearing $23052 \mathrm{cck} / \mathrm{SKF}$, $\mathrm{FTF}=0.45 \mathrm{~Hz}, \mathrm{SBF}=4.73 \mathrm{~Hz}, \mathrm{BPFO}=11.21 \mathrm{~Hz}$ and $\mathrm{BPFI}=13.79 \mathrm{~Hz}$, all normalised to 1 RPS. All the frequencies below the threshold level are considered insignificant.

A dynamic three-level envelope alarm would increase the bearing useful life appreciably and reduce the number of planned and unplanned replacements because the ambiguities, which arise due to changes in speed and load, and cause inaccuracy in the assessment of the bearing condition, will be eliminated.

In many cases, setting and adjusting envelope alarms manually is very difficult and expensive especially when it concerns thousands of measurement points. Now, if these three envelope alarms are normalised to one RPS and produced in a software program, which is automatically adjustable depending on operating conditions, then envelope alarm setting and adjusting for all $\mathrm{n}$ bearings will be easier and cheaper. 
6 MAINTENANCE IMPROVEMENT USING KNOWLEDGE AND EXPERIENCE The failure process o $\mathrm{f}$ a complex machine part such as a rolling element bearing cannot, in general, be described by a single distribution (33). A good understanding of the machine functions and operating procedures, usual deterioration processes and their causes are important to establish and/or improve an effective VBM system. Such understanding can be achieved through concurrent analysis of the monitoring system and machine databases. The author suggests that this analysis be performed in the following sequence:

1. Identification of the significant frequencies and amplitudes.

2. Identification of failure causes, defect development mechanisms and failure modes.

3. Identification of the frequencies which can be used to detect deviations in the product quality, and to follow their development.

4. Relate frequency generation and development to the failure causes, defect development mechanisms and failure modes revealed by damage to replaced bearings. It may also be related to the causes behind deviations in the product quality.

5. With better quality data, the actual vibration levels at failures and other renewals could be analysed statistically and optimised in order to set the replacement vibration level.

This analysis sequence is implemented in two case studies, in paper mills, reported in (33).

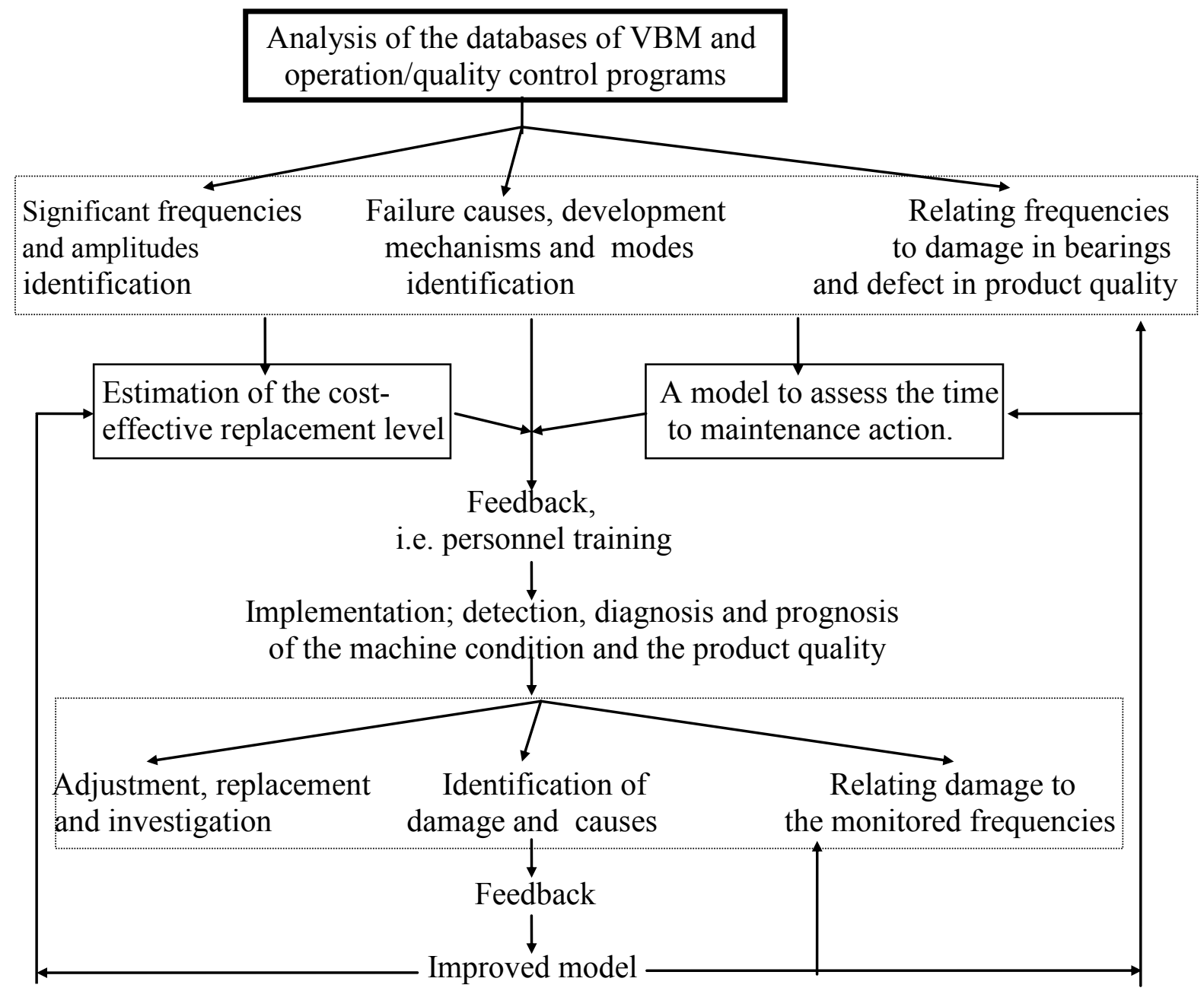

Fig. 2. Maintenance improvement using experience. 
The significant level may be defined as the level indicating changes in the bearing condition. The vibration replacement level can be defined as the maximum allowable level above which the vibration is considered harmful to safety, other machine elements, performance efficiency or product quality.

Such analysis would lead to tools to enable the maintenance engineer to detect deviations in the machine state early and so sustain product quality and output. Maintenance knowledge, experience and method improvement cycles (see Fig.2) improve the diagnosis and prognosis techniques continuously. The early detection of defect initiation would help to control the machine condition when the deterioration level is still within tolerable limits instead of monitoring component condition in order to replace it when its vibration level deviates from normal, i.e. the passive role of monitoring systems (9). Thus, it would be beneficial economically to establish a clear written vibration replacement level-based policy for failure causes detected, in order to control the machine or the component condition and to predict the time to perform more frequent measurements and then when to replace the deteriorated bearing.

\section{DATA GATHERING AND RESULTS FEEDBACK}

Performance of a component can be considered deterministic when it concerns deterioration process and probabilistic attribute as regards the time to failure, under the following constraints:

(1) Function; e.g. the use of identical components for non-identical functions.

(2) Time; operating and stoppage time.

(3) Operating conditions such as loading, machine speed, temperature, etc.

(4) Deterioration process involved, such as fatigue, wear, corrosion and/or deformation.

(5) Component characteristics such as tolerances, material, heat treatment, coating, etc.

(6) Combinations of two or more of the above.

(7) Replacement policy; at failure or as soon as the relevant vibration level exceeds the normal.

These constraints usually cause a large spread in the time to failures even for identical components. Faults develop due to many causes and with high standard deviation because most of the spread is due to different modes, (see Fig.3).

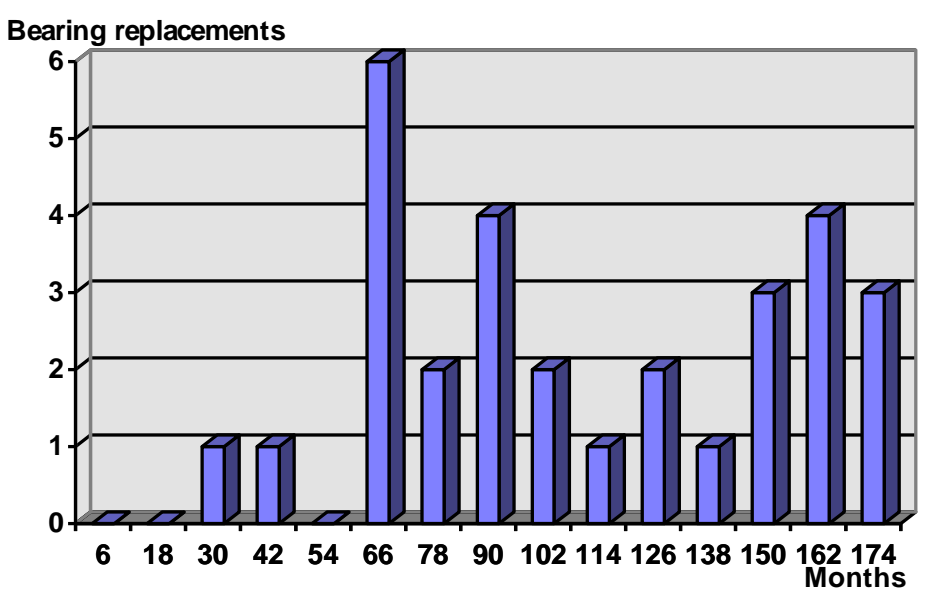

Fig.3. Number of identical bearing replacements versus operating time in months. This histogram is one of the results from two case studies in paper mills (32). 
The required information for distinguishing between failures and censoring is not always available, i.e. the condition of replaced components, and the vibration levels which characterise the damage are not always well defined.

If the records of operating conditions such as loading, felt tensions, machine rotational speed and temperature are not available, it becomes difficult to distinguish whether the increment in the vibration level is due to changed operating conditions or component deterioration $(34,9)$. For large data-sets of better quality, it is possible to identify bearing multiple failure modes using Weibull plotting.

Feedback is defined in BS 3811 (35) as: "A written or oral report of the success or failure of an action to achieve its desired result that can be used to influence design, performance and costs". The applicable results may not be implemented even if the conclusions are reported. Therefore, we believe that the feedback should be completed by practical exercises revealing to the user how these results can be implemented to improve maintenance policy. Thus, in addition to the report, seminars should be given and training workshop should be done to the maintenance staff.

Practical cases are necessary to teach the relevant personnel how to implement the study results effectively and to demonstrate the benefits of collecting and keeping the right data. The major benefits of these changes are to improve maintenance policy through more precise detection, diagnosis and prognosis. The "Catch 22 " is that better data are recorded to show that better data are effective in reducing cost.

\section{COMMENTS AND CONCLUSIONS}

Detecting failure causes at an early stage will make it possible to follow defect development and identify its developing mechanism. This eases the assessment of the component remaining life. After each replacement, diagnosis should be confirmed or adjusted by physical examination of the old bearing. This will lead to continuous improvement in diagnosis and prognosis and, may be, a continuous reduction in the maintenance cost, (see Fig. 2). Thus, records describing all the bearing damage, in addition to the bearings themselves in some cases should be kept.

It is beneficial to keep real-time measurements of the operating parameters particularly RPS and loading to be used in conjunction with the vibration measurements, to eliminate ambiguities in deciding whether the increase in the vibration level is due to more load or more deterioration. A manual search for such information is necessary to correlate changes in the vibration spectrum with operational and environmental conditions. No data should be discarded in future and more detailed records as discussed should be kept.

Succi (1991), discusses three different phases in the bearing life, where the second phase represents about $65 \%$ of bearing total usable life. Therefore, at replacing a bearing as soon as its vibration level exceeds the normal means we are losing approximately $65 \%$ of the bearing mean life, which is the case in general in paper mills. Better diagnosis and prognosis and more accurate identification of the vibration levels, and moments, at defect initiation and replacement help to extend bearing mean operating life.

Using the dynamic envelope alarm, it is possible to identify defect vibration frequencies and to evaluate the state of the bearings easily and effectively. It is shown theoretically to offer later renewal with fewer failures, and therefore lower cost and higher productivity.

\section{ACKNOWLEDGEMENT}

The study is sponsored by Stora Hylte AB and Stiftelse Svenskt Underhållsteknik Centrum, UTC FoU, project 9571. The author is grateful to Prof. D. J. Sherwin for his useful comments and discussions. 


\section{REFERENCES}

1 Collacott, R.A. Vibration monitoring and diagnosis. George Godwin, London 1979.

2 Taylor, James I. Evaluation of machinery condition by spectral analysis. Report from Gardinier Inc. P.O. Box 3269, Tampa, Florida 33601, 1981.

3 Lai, M.S. and Reif, Z. Prediction of ball bearing failures. Ist International Machinery Maintenance Diagnosis Conference and exhibit, pp 122-126, 1989.

4 Bloch, H.P. and Geitner, F.K. Machinery failure, analysis and troubleshooting. Gulf Publishing Company, London 1994.

5 Al-Najjar, B. A new vibration based approach for monitoring rolling element bearing. Nordic Conference on Vehicle and Machine Vibration, Göteborg, Sweden 1994.

6. Al-Najjar, B. On the effectiveness of vibration-based programs. Report 9581, ISSN 14001942, ISRN HV/MASDA/SE/R/--9581--SE, Växjö, Sweden, April 1996I.

7 Heckman, A.T. Vibration monitoring yields big benefits. Chemical Engineering, 126-129, May 1993.

8 Al-Najjar, B. Criteria for the selection of a cost-effective maintenance policy. Report 9585, ISSN 1400-1942, ISRN HV / MASDA / SE / R / --9585--SE, May 1996II.

9 Al-Najjar, B. TQMain; A common database for total Quality maintenance, An approach for continuous reduction in costs of quality products. Journal of Quality in Maintenance Engineering, pp 2-20, Vol 2, Number 3, 1996III.

10 Zaretsky, E.V. Selection rolling-element bearing steels for long-life application NASA. TM. 88881. November 1986.

11 Zaretsky, E.V. Lubricant effects on bearing life. NASA. TM. 88875. Dec. 1986.

12 Succi, George P. Prognostic methods for bearing condition monitoring. Proceedings of the 3rd International Machinery Monitoring and Diagnostics Conference, pp 335-342 Riviera Hotel and Convention Center, Las Vegas, Nevada, USA, 1991.

13 Oakland, S. Total Quality Management. Butterworth-Heinemann Ltd, Linacre House, Jordan Hill, Oxford OX2 8DP, 1993.

14 Oakland, S. and Porter, L. J. Cases in Total Quality Management. Butterworth Heinemann, London, 1994.

15 Jixi, C and Yiyun, H. Vibration analysis and quality detection of ball bearings. Ist International Machinery Maintenance Diagnosis Conference and exhibit, pp572-575, Las Vegas, USA1989.

16 Salyes, R.S. and Macpherson, P.B. Influence of wear debris on rolling contact fatigue. ASTM STP 771:255-275, 1982.

17 Salyes, R.S. and Ioannides, E. Debris damage in rolling bearings and its effect on fatigue life. Trans. ASME J. of Tribology Technol., 1988, 110:26-31.

18 Sunnersjö, C.S. Rolling bearing vibration- The effects of geometrical imperfections and wear. Journal of Sound and Vibration 98(4), 455-474, 1985.

19 Barkov, A. and Barkova, N. Condition assessment and life prediction of rolling element bearings-Part 2. Sound and Vibration, 27-31, September 1995.

20 Scheithe, W. Better bearing vibration analysis. Hydrocarbon Processing, 57-62, July1992.

21 Herraty, A.G. Bearing vibration-Failures and diagnosis. Mining Technology, 51-53, February 1993.

22 Springer C.W. Effects on internal geometry on frequency generated by deep-groove ball bearings. Vibrations vol. 6 No.1, 3-7, March 1990.

23 Taylor, James I. Evaluation of machinery condition by spectral analysis. Report from 
Gardinier Inc. P.O. Box 3269, Tampa, Florida 33601, 1980.

24 Sandberg, M. Envelopanalys- nyckel till kullagerdiagnostik. ' Envelop analysis- A key for ball bearing condition diagnosis' Automation May 1989.

25 Kadushin, D. Roller element bearing fault analysis using envelope detection during an experimental case study. 3rd International Machinery Monitoring and Diagnosis, pp132136, 1991.

26 Taylor, James I. Determination of antifriction bearing condition by spectral analysis. Proc. of Machinery Vibration Monitoring and Analysis Seminar, Sponsored by the Vibration Institute Sponsored, February 1978.

27 White, G. Amplitude demodulation - A new tool for predictive maintenance. Computational Systems Inc., Knoxville, Tennessee, Sound and Vibration, pp 14-19, Sep. 1991.

28 Berry, J. E. How to specify machinery vibration spectral alarm bands. Sounds and Vibration, pp 16-26, September 1990.

29 Sullivan, M.O. Systematic machine-condition monitoring- A case study from Parenco paper mill in Holland. Engineering Cost and Production Economics, 21 (1991) 277- 293.

30 Murphy, T. J. The development of a data collector for low-speed machinery. Profitable Condition Monitoring, pp 251-258. TEC Europe, UK. Kluwer Academic Publisher, England 1993.

31 Al-Najjar, B. Some problems on the selection of a condition based maintenance technique for mechanical systems. Paper I LiU-Tek-Lic- 1990:48, Linköping.

32 Al-Najjar, B and Kumar, U. Effectiveness of vibration-based monitoring systems in paper mills: Two case studies. VTT SYMPOSIUM, COMDEM 97, $10^{\text {th }}$ International Congress and Exhibition on Condition Monitoring and Diagnostics Engineering Management, Vol 1, 48-57, at Helsinki University of Technology, Finland, 1997.

33 Okogbaa, O.G. and Peng X. A methodology for preventive maintenance analysis under transient response. Proceedings Annual Reliability and Maintainability Symposium, IEEE, 335-340, 1996.

34 Lawn, S. and Schuh, D. Paper machine diagnostics with M-B profiling. Paper Machine Diagnostics, Annual meeting, B61-B65, November 1989.

35 British Standard, Glossary of Terms used in terotechnology, BS 3811:1993. 